\title{
Murilo Mendes, a disciplina do indisciplinado
}

Resumo: Com a rebeldia de um autodenominado "menino experimental” Murilo Mendes cria uma distância crítica entre a consciência poética e a sua liberdade de atuação. É uma caracterização que marca, retrospectivamente, a sua produção literária toda, desde os textos iniciais da década de 1930 até os últimos produzidos nos anos de 1960 e 1970. A indisciplina desafia normas e introduz na sua produção inovações temáticas e gráficas, incluindo jogos linguísticos, o kitsch, os grafitos, a miniaturização e novas tendências das artes visuais e comunicação eletrônica. Murilo fica sempre atento à independência da palavra e à musicalidade do texto. A indisciplina vira fonte de expressão e método, portanto, uma disciplina às avessas que percorre a sua imaginação poética.

Palavras-chave: indisciplina, poesia, liberdade, inovação, surrealismo, viagens

Abstract: With the rebelliousness characteristic of his self-description as an "experimental youth," Murilo Mendes creates a critical distance between his poetic consciousness and his liberty of action. With the term, he retrospectively characterizes his entire literary production, from the poetry of the 1930 s to the 1960 s and 70 s. To be indisciplined is to challenge norms and introduce thematic and graphic innovations, such as linguistic play, kitsch, graffiti, miniaturization and new tendencies of visual arts and electronic communications. Murilo is always attentive to the independence of the word and the musicality of poetry. Indiscipline is his self-described source of expression and method, thus a discipline in reverse that motives his poetic imagination.

Keywords: indiscipline, poetry, liberty, innovation, surrealism, travels

Mal posso acreditar que tenho limites, Que sou recortada e definida. Sinto-me espalhada no ar, pensando dentro das criaturas, vivendo nas coisas além de mim mesma. Clarice Lispector, Perto do coração selvagem

Múltiplo, desarticulado, longe como o diabo. nada me fixa nos caminhos do mundo. Murilo Mendes, "Cantiga de Malazarte" 
"Fui, felizmente, enfant terrible [...] Indisciplinado, irregular, insatisfeito. Não aceitava observações, que me pareciam um limite traçado à minha liberdade," escreve o poeta Murilo Mendes no seu livro de prosa, Poliedro (Mendes 1972: 92). Autodenomina-se "menino experimental" (Mendes 1994: 1013-4). Com esta autodefinição tardia, preparada pela autobiografia de 1968, Murilo introduz a persona que rege a sua criatividade e invenção nas letras, de uma atuação iconoclasta e um espírito livre. Com a rebeldia do "menino experimental," cria uma distância crítica entre a consciência do poeta e a sua liberdade de atuação. É uma caracterização com que marca, retrospectivamente, a sua produção literária toda: “[...] a figura do enfant terrible apresenta-se de modo recorrente ao longo da trajetória poética de Murilo Mendes, pontuando-a desde os textos iniciais da década de 1930 até os últimos produzidos nos anos de 1960 e 1970 [...]" (Loureiro 2009: 187). Na autobiografia, $A$ Idade do Serrote, enumera outras qualidades irregulares: “[...] acreditei na ideia desordenadora do demônio. [...] Tornei-me um grande problema para a família, volúvel, irrequieto [...] incomunicável, assinando decretos [...] transferindo-me de planeta [...]" (Mendes 1994: 905, 934). Adota um estilo tão incomum que a autobiografia é considerada "o único livro de memórias capaz de afirmar-se como obra de vanguarda" (Massi apud Pizarro 1995: 331). Murilo se achava, quando pequeno, "[...] um demônio menor, talvez de quinta classe, reduzido, provinciano, ajustado à minha dimensão da época: julgando-o um anarquista, admirava-o secretamente" (Mendes 1994: 905).

Comenta Paulo Rónai, numa resenha, que o livro impressiona "com o ferro em brasa da blague e da sátira [...] provocador, imprevisível, ao mesmo tempo lúdico e cáustico [...]" (Ronai 1969: 6). Em Murilo, a indisciplina e o inconformismo às vezes provocaram um comportamento radical. Luciana Stegagno Picchio, grande amiga do poeta, relata que durante um recital de piano no Teatro Municipal abriu um guarda-chuva para protestar a interpretação musical (Picchio 1994: 23). O choque, segundo Haroldo de Campos, se tornava necessário à criação poética, raiz de obras em que o poeta "é capaz de interiorizar sua própria radicalidade" (Campos 1992: 75).

Numa análise da natureza poética e radical da autobiografia, Antônio Cândido comenta a maneira em que dá "um toque de intemporalidade" ao lugar, ao momento e às cenas: "Assim extravasam os limites e o instante, como convém a um mundo onde a loucura e o milagre são normais, do mesmo modo por que o banal e o quotidiano são miraculosos" (Cândido 1989: 57). São as qualidades indisciplinadas e livres de experimentação e de inovação que acompanham a criatividade de Murilo Mendes e contribuem à sua atuação como pensador e escritor, nas múltiplas dimensões de um puro ser aberto ao grande mundo:

Fiquei sem tradição sem costumes sem lendas

Estou diante do mundo

Deitado na rede mole

Que todos os países embalançam.

(Mendes 1994: 11-12) 
A indisciplina combina o familiar e o estranho, torna a tradição diferente, desafiando normas. Enfocando a obra muriliana no âmbito da poesia modernista, José Guilherme Merquior vê na indisciplina poética "um complexo estilístico," que define como radical, híbrido e heterogêneo, marcado pela "súbita irrupção do extremismo poético [...]." É uma atitude iconoclasta, insubmissa, dissonante, anárquica, erótica e surrealista (Merquior 1994: 11-12). As inovações temáticas e formais continuam do modernismo ao período contemporâneo, com "[...] os jogos linguísticos, o kitsch, os grafitos, a miniaturização e novas tendências das artes visuais e comunicação eletrônica” (Jackson 1990: vi-vii).

Uma das características do modernismo muriliano é a capacidade de capturar a realidade para observação e análise no tempo presente da consciência do poeta, ou seja "kodakar" um momento ou uma situação cultural para integrá-lo na sua antologia poética particular e universal. Na última seção da autobiografia confessa que a fotografia e a colagem formaram seus primeiros cadernos: "Ainda menino eu já colava pedaços da Europa e da Ásia em grandes cadernos. Eram fotografias de quadros e estátuas, cidades, lugares, monumentos, homens e mulheres" (Mendes 1994: 973). Confirma Maria Elisa Thompson que "O olhar do poeta observa, admira e capta imagens que tomam a forma da palavra escrita” (Thompson 2009: 183). Merquior sublinha o caráter imanentista desse olhar, afirmando "um radical estar no mundo" (Merquior 1994: 11).

Em 1928, Murilo publica cinco poemas - retratos da época - na Revista de Antropofagia, "República" na primeira "dentição" e quatro poemas na segunda ("Canção do Exílio," "Cartão Postal," "Vocação" e "Nova Cara do Mundo"). "Cartão Postal," datado "Rio, 1924," ensaia a técnica fotográfica continuada por Oswald de Andrade em "Fotógrafo ambulante," de Pau Brasil (1925). A descrição de um domingo em um jardim público é feita com humor e exagero que beira à fantasia: "[...] bebês arquivados em carrinhos alemães / esperam pacientemente o dia que poderão ler A Escrava Isaura / passam braços e seios com um jeitão / que si Lenine visse não fazia o Soviete." Interioriza o momento a tal ponto que aproxima-se ao conceito de "canibalismo amoroso," codificado por Affonso Romano de Sant'Anna (Sant'Anna 1984).

Luciana Picchio, da Università La Sapienza di Roma, viu na antropofagia "antológica" do poeta uma visão do mundo presente através da sua obra:

[...] um denominador comum capaz de abrasileirar, por assim dizer, todo o conjunto. Falo da antropofagia. Desde A Idade do Serrote, até ao Espaço Espanhol e aos Retratos-Relâmpagos, esta prosa é um eterno processo antropofágico, uma contínua tensão dirigida à captação do Outro, à sua deglutição, não nos moldes aplicados ao Bispo Sardinha, mas na sua reinvenção por Oswald e pela antropofagia brasileira de letras. (Picchio 1980: 11-12)

O humor e a sátira que aplica aos retratos da sociedade brasileira, vistos nos poemas publicados na Revista de Antropofagia, escondem o desejo de documentar materialmente o momento presente, "de capturar o real na forma mais econômica, mais sintética possí- 
vel" (Picchio 1994: 27). Murilo ele mesmo faz uma referência à sua atitude antropofágica na autobiografia, referindo-se ironicamente à infância: "No tempo em que eu não era antropófago, isto é, no tempo em que eu não devorava livros - e os livros não são homens, não contêm a substância, o próprio sangue do homem?" (Mendes 1994: 897). Nos poemas da História do Brasil, de 1932, revisita momentos da formação da brasilidade com imaginação estética,
As pitangas e os cajus
Descansam o dia inteiro.
O céu, de manhã à tarde,
Faz pinturas de baú. (“1500”),

e alude satiricamente a um famoso poema de Carlos Drummond de Andrade:
No meio do caminho
Me atacou um delírio patriótico
Resolvi embarcar para Itararé
No meio do caminho
Entrei num botequim ("1930").

A estrema liberdade em Murilo - “[...] meu não-reconhecimento da fronteira realidade-irrealidade" (Mendes 1980: 83) - é colocada ao serviço de um catolicismo universal e humanista, a outra grande vertente de sua personalidade e arte. Segundo Luciana Picchio, Murilo tinha "fama de católico culto, à maneira francesa, isto é, de amigo de Béguin e dos intelectuais que andavam à roda da revista Esprit [...]" (Picchio 1994: 27). Ao subordinar a indisciplina ao humanismo, encontra uma força unificadora que abre para o poeta o acesso à arte e ao universo. De visita a uma exposição de Matisse em 1947, no Rio de Janeiro, encontra uma lição de comunhão e de compreensão:

[...] essas mesas com toalhas listradas, todos esses objetos cotidianos que entraram definitivamente como coordenadas na obra do pintor, tudo isto me transmite uma ideia de comunhão com as coisas que nos acompanham, arte antipolêmica, anti-didática, arte que repousa sobre uma compreensão dos meios virtuosísticos, sobre uma disciplina da visão, sobre uma personalidade da visão de um artista que pertence à nobre família dos pesquisadores insatisfeitos. (Mendes 1947: 5)

Murilo descreve o impacto do catolicismo como de uma inquietude constante, um "caminho de fogo" e "formidável agulhão da inteligência" (Mendes 1994: 913). Assim, a definição do poeta por Luciana Picchio, "poeta, virgula, católico, virgula, brasileiro" (Picchio 1959: 68), captura a tensão entra a procura do absoluto e a experimentação com 
uma linguagem atual, popular e quotidiana. Os dois lados da sua atuação se encontram seguidamente, exemplificados em um texto de "O olho precoce": "O universo poderá ser reduzido a uma grande metáfora [...] plástica, musical e científica. Todas as coisas implicam signo, intersigno, alusão, mito, alegoria” (Mendes 1994: 973). É o universalismo humanista e católico que fundamenta o seu surrealismo, como confessa na autobiografia: "Movido por um instinto profundo, sempre procurei sacralizar o cotidiano, desbanalizar a vida real, criar ou recriar a dimensão do feérico" (idem: 921). Para o poeta Manuel Bandeira, Murilo foi um "conciliador de contrários," juntando "o eterno ao contingente" (Bandeira 1989: 197). Dessa maneira, Murilo foi capaz de fazer do surrealismo e da indisciplina - aplicando uma visão universalista - uma disciplina, como confirma Merquior: "Do surrealismo é imperativo dizer-se que, para Murilo, ele foi principalmente (por paradoxal que pareça) uma disciplina, um rigor - uma ascese poética” (Merquior 1994: 15).

Os seus gêneros literários preferidos eram "[...] o aforismo, a autobiografia, o diário de viagem, o manifesto e o retrato" (Jackson 1990: 170). Tanto a indisciplina quanto o surrealismo constituíram os seus métodos de trabalho, chegaram a ser as disciplinas que praticou e que estão presentes em toda a sua obra. É com a prática da indisciplina, como método "irregular e insatisfeito," que Murilo criou uma poética que se estendeu consistentemente através do tempo e dos seus escritos, desde o modernismo da década de 1920 até à longa e produtiva residência na Itália, onde se fixou em 1957: "As viagens realizadas em missão cultural e a longa estadia na Itália situam Murilo em novos contextos geográficos, que inspiram sua força criadora e o levam a escrever ininterruptamente até o final da sua vida" (Thompson 2009: 187). Segundo Loureiro, continuou a se conformar à imagem de enfant terrible que construíra de si mesmo, com qualidades de "[...] independência, inteligência, imprudência, excepcionalidade, desajuste, inconformismo, rebeldia, heterodoxia, vanguardismo" (Loureiro 2009: 186).

A indisciplina desse "pesquisador insatisfeito" virou fonte de uma vertente de inovação que se tornou o núcleo de sua expressão como escritor, filósofo e espírito criativo da modernidade, quer na prosa quer na poesia. Observa-se a união dos seus elementos constituintes no poema "Casamento," do livro Poemas (1930):

\footnotetext{
Malazarte pegou numa tesoura e cortou o passado em mil pedaços

o índio, o português, o africano deram o fora

mas os tártaros ainda perturbam o sono das crianças mineiras

e o poeta tem a metade do corpo enfiada na noite do Brasil e da Rússia

porque as cabeças do poeta e dos brasileiros pertencem ao

pensamento de Deus.
}

Trata-se, nas palavras de Luciana Picchio, de "uma já longa travessia que aos demais parecia marcada por certa excentricidade ou, ao menos, pela singularidade" (Picchio 1994: 23). Considera que a obra inteira é unificada por aquilo que pode parecer 
um excesso:

Mas todas as etiquetas só serviriam para fragmentar arbitrariamente um conjunto poético extremamente unitário e sempre marcado pela invenção, pelo 'excesso' poético que é o sinal inconfundível de Murilo Mendes.

Em cada um desses livros há poemas de uma pureza, de uma 'cristalinidade', que poderiam ser escolhidos como pontos altos dessa poesia. (Dias 2001: s/p)

Na indisciplina, Murilo Mendes encontrou sua disciplina mestre, controlada apenas por uma visão poética e pela liberdade possível a uma estética modernista. Cândido considerou Murilo "o poeta mais radicalmente poeta da literatura brasileira, na medida em que praticamente nunca escreveu senão poesia, mesmo quando escrevia sob a aparência de prosa" (Cândido 1989: 57). Foi por continuar a cultivar e praticar tal indisciplina com alto grau de inovação, excedendo limites, que passou, segundo José Guilherme Merquior, "de tangente a eixo da nossa tradição moderna" (Merquior 1994: 11).

A improvisação é uma das técnicas murilianas que melhor comunica a sua indisciplina. Pertence a uma categoria de artista, identificada por Mary Catherine Bateson em um estudo de artistas para quem a composição iguala à vida, que se descobrem enquanto procuram dar forma à sua obra. No estudo, Bateson procura uma gramática e uma estética que fundamentem a improvisação. Sugere que a variação de superfície da improvisação pode esconder convicções e padrões fundos e significantes. Assim, na improvisação Bateson encontra constância, citando versos do poeta e.e. cummings:

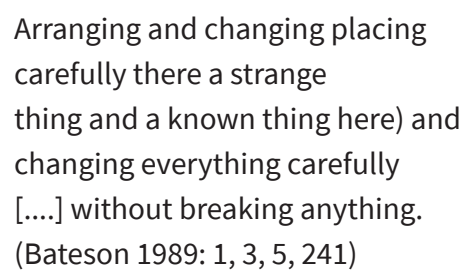

Para Bateson, há alguma coisa em comum entre a rebelião contra as normas culturais e o compromisso com as mesmas, pois frequentemente recombinam materiais familiares de maneira diferente. A improvisação chega a ser autodescobrimento, permitindo ao autor reimaginar o futuro e reinterpretar o passado.

Pela expressão insólita de uma imaginação poética, Murilo pode ser considerado o fabulador do modernismo, dando continuidade a algumas das qualidades que Merquior deslumbra no mestre Machado de Assis: a afinidade pelo aforismo mítico-literário, o uso do parêntese reflexivo, o gosto do inverossímil, o apuro intelectual (Merquior 1975: 11- 
16). Na obra muriliana há um diário de artista que comenta sua época e revela seu pensamento. Pratica a narrativa autobiográfica na qual observa os personagens com um "olho precoce," criando um teatro do ser ou retrato falante de caracterizações, sempre com seu aspecto cômico-fantástico. Ao mesmo tempo, constrói uma história da sua vida e do seu tempo com retratos de poesia em prosa.

Desde $A$ Idade do Serrote, vem reunindo um elenco de personagens e personalidades para os seus Retratos-Relâmpagos (45 da 1.a série, 1965-66; 29 da 2.a série Roma 1973-74, incluindo Pound, Duchamps, Magritte e Varese, entre os brasileiros Villa-Lobos, Guimarães Rosa, Tarsila) e nos 38 retratos de A Invenção do Finito (1960-70), para compilar um dicionário de bolso pessoal. Fazendo contraponto aos retratos são os 754 aforismos de Os Discípulos de Emaus (1945), com continuação em Poliedro, sobretudo nos aforismos do "Setor Texto Délfico," verdadeiras iluminações ou epifanias, tal uma coleção de ideias e imagens tiradas da imaginação: "Viajar na eternidade com numerosas trabalhosas escalas no tempo" (Mendes 1994: 1046).

Pode-se notar a presença da indisciplina muriliana, como observa Cândido, na técnica de "tema-variação," caracterizada por modulações e mudanças sucessivas ao nível de "tonalidade, maneira, composição [...] sem ligações, nem coerência externa." Cria um jogo sintático que abre sucessivamente esferas maiores e significados plurais (Cândido 1989: 57-58). Na autobiografia, os períodos elípticos que comunicam o nascimento do poeta - "A multiplicação dos pais. A multiplicação dos peitos. A multiplicação dos pães. A multiplicação dos pianos" (Mendes 1994: 895) - se multiplicam na sua obra. No "Setor Microlição de coisas," de Poliedro, por exemplo, reaparecem os períodos elípticos em "O copo:" "A vibração do copo. A viração do copo. A vidração do copo. A vinhação do copo" (idem: 998). Também na definição do medo: "O medo fértil. O medo, téssera de identidade de todos os homens. $\mathrm{O}$ medo do mito. $\mathrm{O}$ medo do mato. O medo do morto. $\mathrm{O}$ medo do medo"(idem: 1216). Num poema autobiográfico de 1930, "Mapa," Murilo já lançara a expressão que melhor descreve o espírito de improvisação do modernismo: "Viva eu, que inauguro no mundo o estado de bagunça transcendente."

Nos 18 anos passados na Itália, Murilo refinou um estilo de poesia-prosa, enfocando espaços geográficos (“O Uruguai é um belo país da América do Sul, limitado ao norte por Lautréamont, ao sul por Laforgue, a leste por Supervielle. O país não tem oeste." (idem: 1023)), experimentando com gêneros inventados - os grafitos, murilogramas e retratos-relâmpago - e escrevendo a autobiografia insólita. Os gêneros inventados - os grafitos, os murilogramas, os retratos-relâmpago - evidenciam o interesse do poeta pela tecnologia e pela geometria da forma. Além da autobiografia inovadora, praticou uma poesia-prosa sui generis em livros dedicados a uma visão geográfica das suas andanças pelo mundo: Contemplação de Ouro Preto, Carta Geográfica, Siciliana, Tempo Espanhol, Espaço Espanhol, Janelas Verdes. Segundo Luciana Picchio, palavra-som-geografia-cor sempre faziam parte em Murilo de uma mistura de vida e literatura: "um aspecto de Murilo prosador, sempre inspirado pelo desejo de 'fixar' em som e sentido uma estação da vida [...]"(Pic- 
chio 1994: 29). Da mesma maneira que retrata personalidades ligadas à família na autobiografia, com micro-capítulos dedicados a cada nome - as amas de leite, Etelvina e Sebastiana, o músico que tocou na casa do pai, Isidoro da Flauta - nos Retratos-Relâmpago define e assimila um elenco de personagens mundiais. São 45 nomes da 1 . ${ }^{a}$ série, sendo uma história sincrônica das artes e humanidades, composta de escritores, filósofos, artistas, músicos e performers. Formam um panorama do mundo ocidental, passando do classicismo até ao presente, de Homero a Villa-Lobos, Varèse e Elsie Houston. Passa a criar outra família ou elenco universal, mostrar o pano de fundo da sua formação intelectual e apresentar os companheiros de atuação modernista. Luciana Picchio acha que a série representa uma "forma extremada dessa antropofagia poética, em que o Outro procura ser definido [...] com uma curiosidade que às vezes se torna conivência, simbiose, parasitismo" (Picchio 1994: 12).

Nos micro-retratos observa-se o mesmo humor irreverente dos poemas na Revista de Antropofagia, acompanhados por uma leve sátira, ou descrença, da série histórica em que o poeta se investe. Encontra-se nos Retratos-Relâmpago a mesma linguagem sintética, de sequências onomatopaicas e metonímias experimentais presentes nos poemas "antropófagos" de 1928-29:

DANTE: Dante viu, retroviu, previu, introviu, postviu, cosmoviu

$[\ldots]$

VOLPI: Volpicor Volpiespaço Volpitempo Volpiaberto área de recorte exato campo preciso da cidade pilotado programado

[...]

RAUL BOPP: A tribo dos Poracrameerãs dos Tocantins a tribo dos Vaivais a tribo dos Umãs a tribo dos Amauacas [...]

(Mendes 1994: 1201, 1216, 1253)

Por ser indisciplinado e aberto à experimentação, é sempre atento à independência da palavra e à musicalidade do texto. Coloca palavras em estruturas geométricas, trabalha com semelhanças paronomásticas entre palavras, aliterativas e gráficas, criando significados eufônicos e esculturais, além de léxicas. Segue um "impulso irresistível de subverter a lógica e a linguagem da prosa descritiva pela introdução de conteúdo extraliterário - da eletrônica e da cultura de massa - e de práticas encontradas nas artes plásticas das vanguardas europeias" (Jackson 1990: 91).

O indisciplinado o insatisfeito Murilo Mendes manteve-se sempre fiel apenas à poesia e à imaginação, elaborando na sua geometria poliédrica e cristalina, e na sua temática católica universalista, um propósito estético singular, e de uma in-disciplina transcendental: "para tocar a flauta mágica / para concluir a palavra / [...] para desmontar o tempo / para completar minha cota terrestre" (Mendes 1980: 403).

NOTA 
* Kenneth David Jackson é professor de literaturas e culturas luso-brasileiras e lusófonas da Universidade de Yale. Entre os seus livros, Cannibal Angels: Transatlantic Modernism and the Brazilian Avant-Garde, Machado de Assis: A Literary Life, Adverse Genres in Fernando Pessoa, Luís de Camões and the First Edition of Os Lusíadas e Sing Without Shame: Oral Traditions in Indo-Portuguese Creole Verse.

\section{BIBLIOGRAFIA}

Almeida, Aline Novais de (2019), "Manequim de pássaros: ritmo, corpo e metamorfose em Murilo Mendes", Tese de doutoramento. Universidade de São Paulo.

Bandeira, Manuel (1989), "Saudação a Murilo Mendes", Estrela da Vida Inteira, 16a ed., Rio de Janeiro, José Olympio: 197.

Bateson, Mary Catherine (1989), Composing a Life. New York, Atlantic Monthly Press.

Campos, Haroldo de (1992), "Murilo e o mundo substantivo", Metalinguagem \& outras metas. 4. ${ }^{a}$ ed. São Paulo, Perspectiva: 65-75.

Cândido, Antônio (1989), "Poesia e ficção autobiográfica", A educação pela noite \& outros ensaios. São Paulo, Editora Ática: 51-71.

Dias, Maurício Santana (2001), "O visionário distante", Folha de S. Paulo (13/5/2001), mais! Garcia, Waldimir Antônio da Costa (1990), "O cometa e o bailarino: a modernidade em Murilo Mendes", Diss. de Mestrado, UFSC.

Jackson, Elizabeth Anne (1990), "Murilo Mendes: From Modernism to Microprose", Tese de doutoramento, U. Texas Austin.

Leão, Gustavo Henrique de Souza (2012), "Poesia panaceia: o verso essencial de Murilo Mendes", Dissertação de Mestrado, Universidade Federal de Alagoas.

Loureiro, Jayme Eduardo (2009), "A formação de um enfant terrible: poetização e resistência em A Idade do Serrote", Tese de doutoramento, U. São Paulo.

Massi, Augusto (1995), "Murilo Mendes: a poética do poliedro", in Pizarro, Ana (org.), América Latina: palavra, literatura e cultura, vol. 3, Unicamp: 331.

Mendes, Murilo (1947), "Matisse", Letras e Artes (12 out. 1947): 5.

-- (1968), A idade do serrote. Rio de Janeiro, Sabiá.

-- (1970), Convergência. São Paulo, Duas Cidades.

-- (1972), Poliedro. Rio de Janeiro, José Olympio.

-- (1973), Retratos-relâmpago: 1. a série. São Paulo, Conselho Estadual de Cultura.

-- (1977), Ipotesi. Luciana Stegagno Picchio (org.), Milão, Guanda. 
-- (1980), Transístor: Antologia de Prosa. Rio de Janeiro: Nova Fronteira.

-- (1994), Murilo Mendes: Poesia Completa e Prosa. Volume único. Org. e preparação do texto por Luciana Stegagno Picchio. Rio de Janeiro, Nova Aguilar.

Merquior, José Guilherme (1975), "Prefácio", in Machado de Assis. Várias Histórias. Rio de Janeiro, Civilização Brasileira: 11-16.

-- (1994), "Notas para uma Muriloscópia”, in Murilo Mendes: Poesia Completa e Prosa. Volume único. Org. e preparação do texto por Luciana Stegagno Picchio. Rio de Janeiro, Nova Aguilar: 11-21.

Picchio, Luciana Stegagno (1959), "Itinerário poético de Murilo Mendes”, Revista do Livro 16 (dez. 1959): 61-73.

-- (1980) "Prosas de Murilo Mendes", in Transístor: Antologia de Prosa. Rio de Janeiro, Nova Fronteira: 11-22.

-- (1994), "Vida-Poesia de Murilo Mendes", in Murilo Mendes: Poesia Completa e Prosa. Volume único. Org. e preparação do texto por Luciana Stegagno Picchio. Rio de Janeiro, Nova Aguilar: 23-31.

Pizarro, Ana (org.) (1995), América Latina: palavra, literatura e cultura, vol. 3, Unicamp.

Ronai, Paulo (1969), “A nova face de Murilo Mendes”, O Estado de São Paulo (06 dez. 1969), Suplemento literário, ano 14, n. 651.

Sant'Anna, Affonso Romano (1984), O canibalismo amoroso: o desejo e a interdição na nossa cultura através da poesia, São Paulo, Brasiliense.

Thompson, Maria Elisa Escobar (2009), "Minha irmã epistolar: cartas do poeta visionário Murilo Mendes a Virgínia Mendes Torres”, Tese de doutoramento. U. São Paulo. 